\title{
Neuralgic amyotrophy with bilateral diaphragmatic palsy
}

\author{
AN GRAHAM, PD MARTIN, LF HAAS \\ From the Department of Medicine, Wellington Hospital, Wellington, New Zealand
}

Neuralgic amyotrophy is a well recognised condition of unknown aetiology with characteristic clinical features.' These include severe pain in the shoulder region, followed within hours or weeks by motor or sensory abnormalities, or both, in the distribution of the cervical roots or nerves. Unilateral disease is more common clinically but if electromyographic (EMG) studies are performed bilateral disease is often found. ${ }^{2}$

\section{Case report}

In late 1981 a previously well 35 year old man presented with two weeks' orthopnoea and increasing exertional breathlessness such that he became breathless after walking $50 \mathrm{~m}$ on the level. Four days before the onset of breathlessness severe persisting pain in the right shoulder region occurred. This had developed four days after unaccustomed physical activity. There was no relevant past history, preceding viral illness, recent vaccination, or systemic upset. When he was examined in the supine position the respiratory rate was 40 per minute but it decreased to 24 per minute after he stood up. Breath sounds at the left lung base were decreased. Sensation was diminished on the lateral border of the right upper limb, from shoulder to thumb (corresponding to C5-6 dermatomes). Both triceps, left supinator, and right biceps jerks were diminished. Chest radiography showed collapse and consolidation in the left lower zone. This did not improve with antibiotics and physiotherapy. Bronchoscopy and cervical spine radiographs were normal. Over the next few weeks the dyspnoea remained stable, but the patient became aware of weakness of right shoulder abduction and elbow flexion. During this period paradoxical inspiratory abdominal movement was noted. Diaphragmatic function was evaluated: vital capacity (VC) was 1.01 supine and 2.11 erect (predicted 4.31 ). The change in transdiaphragmatic pressure measured by oesophageal manometry during a maximum inspiration was zero (predicted $>25 \mathrm{~mm} \mathrm{Hg}$ ). Percutaneous stimulation of left and right phrenic nerves ${ }^{3}$ produced no electrical response from the diaphragm. Right sural, lateral popiteal nerve motor, median, ulnar, and radial nerve motor and sensory conduction studies all gave normal results. Neither clinical improvement nor change in the VC supine-erect gradient occurred with aminophylline or oral theophylline despite maintenance of serum concentrations of the drug within the therapeutic range for six weeks. The right shoulder pain persisted, but was absent three months later. Five months after the onset of symp-

Address for reprint requests: Dr AN Graham, Department of Medicine, Wellington Hospital, Wellington, New Zealand.

Accepted 4 February 1985 toms some loss of bulk and tenderness of the left vastus lateralis muscle was noted, but no weakness or sensory or reflex abnormality was present. The muscle subsequently regained its size over the next few months.

The patient was reviewed three years after the onset of symptoms. He had suffered occasional lower respiratory tract infections but gradual functional recovery had taken place, though this was incomplete. He was able to jog several kilometres, and he no longer experienced orthopnoea. Paradoxical abdominal movement with respiration was no longer apparent. Minimal weakness of right shoulder abduction and elbow flexion remained, as did a small sensory deficit on the lateral forearm. Upper limb reflexes were normal. The chest radiograph still displayed a higher left diaphragm. VC was now 2.01 supine and 2.31 erect. The transdiaphragmatic pressure difference during a maximum inspiration was $18 \mathrm{~mm} \mathrm{Hg}$. EMG examination, including computerised analysis of the EMG interference pattern ${ }^{4}$ of the right biceps and extensor communis digitorum (a clinically unaffected muscle), showed changes of chronic denervation.

\section{Discussion}

Unilateral or bilateral diaphragmatic palsy may occur with neuralgic amyotrophy, but there are few published reports. ${ }^{2}$ The condition is not mentioned in a major textbook of respiratory medicine ${ }^{5}$ or in one frequently quoted list of causes of diaphragmatic palsy. ${ }^{6}$ Patients with neuralgic amyotrophy affecting the diaphragm usually present with respiratory insufficiency. The often associated upper limb pain is an important diagnostic clue. The diagnosis should be considered in any case of unexplained diaphragmatic palsy; the prognosis is good, ${ }^{127}$ although recovery may take several years. Most other cases of diaphragmatic palsy, whether or not the cause has been identified, have a poor prognosis. ${ }^{6}$ EMG studies, as shown in this case and others, may show denervation in clinically unaffected upper limb muscles. ${ }^{128}$ These electrical changes may reverse and the muscles return to normal, ${ }^{7}$ but this does not always occur. ${ }^{2}$ Medical treatment has been ineffective, but intercurrent complications of diaphragmatic palsy have to be dealt with while recovery is awaited. Neuralgic amyotrophy affecting lower limbs has been reported in otherwise typical cases, ${ }^{89}$ and a similar syndrome of the lumbosacral nerve fibres has recently been described. ${ }^{10}$ The meaning of the transient left lower limb changes seen in this patient is uncertain but they may have been part of his illness.

This patient's history, the results of investigations, and the clinical course are characteristic of the syndrome of neuralgic amyotrophy with bilateral diaphragmatic palsy. The case serves as a reminder that neuromuscular disease 
as a cause of impaired respiratory function should always be considered.

We are grateful to Peter Keller and Chris Ward for translations, and Kathleen Hendricks for typing the manuscript. This case was presented at the 1984 meeting of the New Zealand Thoracic Society.

\section{References}

1 Gathier JC, Bruyn GW. Neuralgic amyotrophy. In: Vinken PJ, Bruyn GW, eds. Handbook of clinical neurology. Vol 8. Amsterdam: North Holland Publishing Company: 77-85.

2 Tsairis P, Duck PJ, Mulder DW. Natural history of brachial plexus neuropathy: report on 99 cases. Arch Neurol 1972; 27: 109-17.
3 Newsom Davis J. Phrenic nerve conduction studies in man. J Neurol Neurosurg Psychiatry 1967;30:420-6.

4 Stalberg E, Chu J, Bril V, Nandedkar S, Stalberg S, Ericsson M. Automatic analysis of the EMG interference pattern. Electroenceph Clin Neurophysiol 1983;56:672-81.

5 Fraser RG, Pare JAP. Diagnosis of diseases of the chest. 2nd ed. Philadelphia: W B Sanders, 1978:1872-3.

6 Piehler JM, Pairolero PC, Gracey DR, Bernatz PE. Unexplained diaphragmatic paralysis: a harbinger of malignant disease? J Thorac Cardiovasc Surg 1982;84:861-4.

7 Devathason G, Tong HI. Neuralgic amyotrophy: criteria for diagnosis and a clinical with electromyographic study of 21 cases. Aust NZ J Med 1980; 10: 188-91.

8 Wurmser P, Kaeser HE. Zur neuralgischen Amyotrophy. Schweiz Med Wochenschr 1963;93:1393-403.

9 Spillane JD. Localised neuritis of the shoulder girdle. Lancet 1943;ii:532-5.

10 Evans BA, Stevens JC, Dyck PJ. Lumbosacral plexus neuropathy. Neurology (Minneap) 1981;31:1327. 